\title{
EDITORIAL
}

\section{Liedi Bariani Bernucci}

Editora de TRANSPORTES

Estamos assumindo um novo biênio (1999/2000) de atividades da ANPET - Associação Nacional de Pesquisa e Ensino em Transportes, com nova diretoria, com o objetivo de dar continuidade ao trabalho que a associação tem realizado, congregando pesquisadores, docentes, profissionais, alunos, universidades, empresas, entidades e órgãos voltados aos transportes.

A ANPET tem exercido importante papel como formadora de opinião, mantendo um congresso anual e sua revista TRANSPORTES, de periodicidade semestral, como veículos que fomentam a discussão e a reflexão da comunidade científica e técnica.

Neste novo período que se abre, estamos trazendo o volume 7 - número 1 da TRANSPORTES com três Artigos, sendo o primeiro deles de autoria de Núñez, Ceratti, Sukahara e Oliveira, que mostra uma excelente pesquisa, rica em dados e conclusões, sobre o comportamento de pavimentos testados em verdadeira grandeza na Área de Testes da UFRGS/DAER. O segundo artigo, de autoria de Murgel e Gualda, baseado na dissertação de mestrado da primeira autora, é uma contribuição para a solução do problema de formação de trens; o artigo apresenta a heurística utilizada e descreve os resultados de uma aplicação a um caso real. O terceiro artigo, de autoria de Cybis, Lindau e Araújo, apresenta uma proposta metodológica inovadora para a análise do impacto de um grande complexo comercial, importante pólo gerador de tráfego, também baseada em um estudo de caso real desenvolvido pelo grupo de Transportes da UFRGS. 
Na seção Panorama Profissional, temos a contribuição de Câmara, pesquisador brasileiro radicado na Inglaterra, sobre os resultados do Projeto Momentum, esforço cooperativo europeu visando aumentar os níveis de mobilidade nas cidades, reduzindo simultaneamente a dependência do automóvel.

Na seção Resenha, Cunha elabora, como contribuição para a área de logística, uma profunda e interessante descrição crítica do livro The Logic of Logistics: Theory, Algorithms and Applications for Logistics Management, de J. Bramel e D. Simchi-Levi.

Finalmente, na seção Eventos, Lindau e Strambi, apresentam um relato do X Congresso Panamericano de Engenharia de Tráfego e Transportes, realizado em 1998 na Espanha, destacando características particulares desse evento, importante fórum de intercâmbio científico da comunidade latino-hispano-íbero-americana. O próximo Congresso Panamericano realizar-se-á no Brasil, em Gramado, RS, em novembro do ano 2000, contando com atividades conjuntas ao Congresso da ANPET daquele ano.

Gostaríamos de expressar nossos sinceros agradecimentos à Ipiranga Asfaltos $S A$, em especial ao Dr. Wellington S.L. Sandin e ao Dr. Paulo Brandi Sastre, que, acreditando na importância da ANPET, contribuíram efetivamente para a viabilização deste número, arcando com os custos de editoração da revista e impressão da capa; à Escola Politécnica da Universidade de São Paulo, em especial ao seu Diretor, Prof. Dr. Antonio Marcos de Aguirra Massola, que tem se empenhado na divulgação das atividades de ensino, pesquisa e prestação de serviços realizadas pelo corpo docente e de pesquisadores da instituição que dirige, e que, pela confiança depositada na revista, disponibilizou a gráfica da Escola para a impressão da TRANSPORTES; finalmente, ao Laboratório de Tecnologia de Pavimentação do Departamento de Engenharia de Transportes da Escola Politécnica da USP, coordenado por esta editora, que arcou com parcela dos custos para impressão da revista. 
Como editora, gostaria de agradecer meus colegas co-editores da TRANSPORTES, Prof. Dr. Licínio da Silva Portugal da COPPE/UFRJ e Prof. Dr. Orlando Strambi da EPUSP, pelo auxílio e companheirismo em todos os momentos, para que com sucesso trouxéssemos a TRANSPORTES até nossa comunidade. 